\title{
A EDUCAÇÃO NA ORIENTAÇÃO DOS PAIS DE BEBÊS E CRIANÇAS SURDAS
}

\author{
Erica Aparecida Garrutti-Lourenço ${ }^{\mathrm{i}}$ \\ Sandra Regina Leite de Camposii \\ Jessica de Oliveira Holanda ${ }^{\text {iii }}$
}

\begin{abstract}
RESUMO: Este estudo tem como objetivo analisar o cotidiano escolar de uma criança com deficit auditivo, nas suas relações com a família, nas formas como as professoras lidavam com a sua surdez, bem como no acompanhamento de uma graduanda em Pedagogia. Aos dois anos, a criança foi matriculada em uma instituição particular de Educação Infantil. Como fonte de dados, foram utilizados os registros do diário de campo da mediadora pedagógica e uma entrevista com a mãe. Os relatos foram analisados na perspectiva dos estudos de Vygotsky, ressaltando o papel do mediador no desenvolvimento do sujeito, e do seu entorno interacional na construção de saberes. Este estudo revela como a família avançou, de um início marcado pela negação da condição do filho na escola, até o seu reconhecimento como surdo.
\end{abstract}

Palavras-Chave: Implante coclear, Surdez, Libras, Criança surda, Educação bilíngue.

\section{THE EDUCATION IN GUIDING PARENTS OF DEAF INFANTS AND CHILDREN}

\begin{abstract}
This study objective is to analyze the school routine of a child with hearing loss, in his relations with the family, in the ways in which the teachers dealt with his deafness, as well as in the monitoring of a graduate student in Pedagogy. At two years of age, the child entered a private school. As data source, the records of the field diary of the pedagogical mediador were used and an interview with her mother. The reports were analyzed from the perspective of Vygotsky's studies, highlighting the role of the mediator in the development of the subject, and considering their interaction environment in the construction of knowledge. This study reveals how the family progressed, from a beginning marked by the negation of the son's condition in school, to the search of alternatives that would normalize it, to reestablish the child's speech and, finally, to make the parents recognize the son as deaf.
\end{abstract}

Keywords: Cochlear implant, Deafness, Brazilian Sign Language, Deaf child, Bilingual education.

2020 Bargas; Ayoub; Assaritti, Scarazzatto, Assis. Este é um artigo de acesso aberto distribuído sob os termos da Licença Creative Commons Atribuição Não ComercialCompartilha Igual (CC BY-NC-4.0), que permite uso, distribuição e reprodução para fins não comerciais, com a citação dos autores e da fonte original e sob a mesma licença 


\section{INTRODUÇÃO}

A Constituição da República Federativa do Brasil de 1988 consiste num marco normativo importante para conquista do direito de acesso e permanência na Educação Infantil. As crianças adquiriram o direito de serem educadas, em creches e pré-escolas, passando a serem consideradas, portanto como cidadãs, sujeitos de direitos. Todas as crianças têm direito a essa modalidade. Sendo assim, as instituições devem se organizar para acolhê-las e oportunizar possibilidades de trocas e de aprendizagem para que, desse modo, destaquem-se os princípios da inclusão.

Nesse movimento sempre contínuo de uma Educação Infantil que seja para todos, despontam estudos que destacam o acesso por um público específico: os bebês e as crianças surdas (ANDREIS-WITKOSKI, 2014, GURGEL, et al, 2016), ainda que tais estudos se desenvolvam numa frequência restrita perante os desafios revelados cotidianamente. $\mathrm{O}$ planejamento e a operacionalização de propostas educacionais para a educação da infância de crianças surdas encontram limites e dificuldades.

Entre o previsto legalmente quanto à inclusão e o atendimento realizado efetivamente, há um grande distanciamento, a se iniciar pelo acesso tardio à língua que permeará as trocas cotidianas da criança surda ao longo de toda sua vivência escolar, e a partir de marcos legais que trazem especificações sobre o desenvolvimento da língua e a vida escolar.

O direito a uma educação bilíngue para a criança surda, tendo a Língua Brasileira de Sinais (Libras) como primeira língua e o português escrito como segunda língua, passa a ser reconhecido pela sociedade essencialmente a partir da década de 1990, ganhando destaque nos anos 2000, quando importantes normativas legais são sancionadas, como a Lei n. 10.436, de 24 de Abril de 2002 e o Decreto n. 5.626, de 22 de Dezembro de 2005, que dispõem sobre o reconhecimento da Libras, seu ensino, uso e difusão no Brasil, e trazem orientações básicas quanto à educação bilíngue. Importantes documentos acerca da inclusão escolar fazem menção a tais normativas ao se referirem à educação do aluno surdo (BRASIL, 2008; 2011; 2015). Mesmo com esse reconhecimento legal, há um longo percurso a ser trilhado para a garantia desse direito, sobretudo em razão da amplitude de mudanças necessárias para a organização de projetos educacionais bilíngues.

A educação bilíngue precisa ser cotejada numa dimensão política de duplo valor, pondera Skliar (2016, p. 8): “o 'político' como construção histórica, cultural e social, e o 'político' entendido como as relações de poder e conhecimento que atravessam e delimitam a proposta e o 
processo educacional". Nesse sentido, temos como grande obstáculo na construção de projetos de educação bilíngue: a ausência de políticas linguísticas e multiculturais, que retratem e valorizem a diversidade de línguas presentes no Brasil e, dentre elas, a Libras (QUADROS, 2015; SILVA, 2015). Explicita-se assim que a legislação por si não traz consigo as transformações sociais demandadas pelos grupos minoritários, uma vez que a legislação é consequência e não causa essas demandas.

É fato recorrente o silenciamento de línguas minoritárias, o que se dá em um processo nem sempre explícito, anunciado para e pelos sujeitos. Em vez de se interditar a circulação da Libras, nega-se a possibilidade de usufruir de um ambiente em que se permita adquirir essa língua. O aprendizado da língua de sinais, quando muito, é tolerado com a expectativa de que melhor seja a fluência e uso da língua majoritária, afirma Silva (2015).

Ao sujeito surdo, nega-se a oportunidade de constituir na e pela Libras, língua essa acessada pela modalidade visuoespacial - em atendimento a sua forma visual e manual de compreender e interagir com o mundo e que, por isso, melhor instrumentaliza sua organização cognitiva. A essa língua comumente confere-se o status de língua secundária, apreendida se os sujeitos não obtiverem sucesso no domínio da língua oral, dominante no ambiente de entorno. Desse modo, no caso de bebês surdos que nascem em lares formados por pais ouvintes, é muito comum que seja transcorrido um longo período até a sua matrícula numa instituição de Educação Infantil na expectativa de que primeiro aprendam a língua oral e muito mais tempo se passa até que a criança seja descoberta na Libras, e em associação ao fracasso na língua de entorno.

Da perspectiva exposta acima, concebemos a língua de sinais como a língua que permitirá aos bebês surdos constituírem-se como seres de linguagem, sociais, uma vez que encontrarão as maiores possibilidades de trocas numa língua visuoespacial, acessível plenamente. Como consequência, será a Libras que fornecerá meios para que encontrem seu lugar no mundo, de crianças surdas sinalizantes; que, por isso, podem, então, viajar pelo mundo da imaginação, da fantasia, do aprendizado, da construção de sentidos sobre a natureza e sociedade e que têm muito a dizer junto a seus pares coetâneos e adultos.

A descoberta tardia da criança surda sinalizante se relaciona, em partes, com o não domínio dessa língua entre as pessoas do círculo de convívio dos bebês e das crianças surdas, ou seja, grande parte deles só terá contato com a sua língua de conforto na escola, isso em contextos em que se preconize o bilinguismo (Libras e Língua Portuguesa). Outro fator de grande impacto consiste no fato de que as línguas orais são privilegiadas na sociedade, normalmente são as únicas a circularem em larga escala nas comunidades, nos meios sociais. 
Na perspectiva de Higgins (1980), o sujeito surdo ao viver em um mundo ouvinte, sempre relata experiências frustrantes e embaraçosas e é na sua comunidade que ele vai existir sem vergonha de ser Surdo, é nela que se sente confortável e confiante, é este lugar que lhe garante, ainda que parcialmente, a experiência de suficiência, que não experimenta no mundo ouvinte.

Numa linha oposta a essa descoberta do bebê e da criança surda sinalizante, encontra-se a abordagem médico-tecnicista que, repetida por incontáveis vezes ao longo dos séculos, e ainda presente na atualidade, tornou-se o protocolo de encaminhamento de filhos surdos de pais ouvintes, para a escolha do melhor caminho a ser seguido, tanto no que se refere à escolha da língua quanto à escolha da educação de seus filhos.

Atrelada à clínica terapêutica, a educação de surdos, aproximadamente no final do século $\mathrm{XX}$, esperava dessa instituição as orientações para que pudesse traçar o seu fazer pedagógico, uma vez que, na perspectiva dominante, o aprendizado da leitura e da escrita tinha uma íntima relação com a performance da fala da criança, que, ainda que tenha nascido surda, era considerada um paciente a ser reabilitado. O termo reabilitado trás consigo a ideia da normatividade, são considerados normais os sujeitos que estão dentro de um padrão social e clinicamente estabelecido. Assim, o sujeito com deficit auditivo deveria ter nascido com aparatos suficientes para o desenvolvimento da fala; desprovido da audição, ele deveria, então, retomar o caminho da norma.

Mas, por que estamos aqui conjugando o verbo no passado se os fatos acima descritos ainda são, via de regra, corriqueiros na vida de uma família que se vê, pela primeira vez, frente a um sujeito surdo, quando nasce seu filho? Ou seja, o protocolo médico-tecnicista ainda se repete, mesmo que sustentado pelos avanços tecnológicos representados, hoje, pelo implante coclear (IC), pelo transplante de células-tronco ou por outros aparatos que a tecnologia nos oferece com uma velocidade surpreendente. O objetivo final do protocolo continua sendo o mesmo, uma fala que se assemelhe, o mais próximo possível, da fala natural, isto é, de quem ouve. Mantém-se, nas palavras de Silva e Favorito (2009, p.16), “a representação dos surdos como anormais, como sujeitos deficientes que devem ser submetidos a tratamento".

Tendo em vista essas perspectivas apresentaremos o caso de uma família que, a partir da atuação de uma mediadora pedagógica, pôde ressignificar sua percepção sobre o filho, podendo, assim, estar sensível às necessidades claramente expostas por ele, em suas participações na rotina de uma turma da Educação Infantil. 
Objetivamos mostrar que a língua de sinais pode ser apresentada à família e à criança por profissionais da educação que, embora não estejam tecnicamente prontos - principalmente a mediadora pedagógica que está em formação no curso de Pedagogia, encontram caminhos que os levam a compreender os sujeitos com os quais atuam, tomando como referência a criança, seu bem-estar e sua relação com o entorno social, assim como o que estudava em sua licenciatura, ainda em curso.

O nascimento de um filho pressupõe situações de escolhas, que vão desde o tipo de amamentação às cores das roupas, sem falar na difícil decisão de escolher um nome entre tantas possibilidades. No entanto, se a criança foge do padrão socialmente esperado, os aspectos comuns, a todos que já passaram pela experiência de ter um filho, tornam-se um aprendizado solitário. Ao ter um filho surdo, a criança, que viria a ser sua "imagem e semelhança", passa a ser um desconhecido, e para exercer o papel de pais é necessária a orientação de médicos e terapeutas. E como já dito anteriormente, os encaminhamentos tomam o papel dos pais e passam a rascunhar a infância da criança surda.

É neste contexto que os deveres dos pais, inscritos na legislação pelo "pátrio poder”, são atravessados pelas representações sociais do deficit e da deficiência. Neste relato, a expressão déficit aparece como uma marca da limitação biológica que impõe a necessidade de normatização do bebê. A expressão deficiência, por sua vez, adota uma concepção social, segundo a qual a deficiência resulta "[...] da interação entre pessoas com deficiência e as barreiras devidas às atitudes e ao ambiente que impedem a plena e efetiva participação dessas pessoas na sociedade em igualdade de oportunidades com as demais pessoas", conforme define o Decreto n. 6.949, de 25 de Agosto de 2009. No contexto experienciado pelas famílias, a necessidade da normatização frequentemente se impõe e esse será o recorte de análise do fragmento de história que apresentamos neste estudo de caso.

Pautaremos as análises que seguem em fragmentos derivados do diário de campo da mediadora pedagógica e uma das autoras deste estudo, referida pela escola como acompanhante terapêutica ${ }^{4}$, onde constam registros de cenas e reflexões decorrentes de sua atuação com uma criança surda, em três dias da semana, durante um período de seis meses.

Em tal diário de campo, as observações da mediadora pedagógica eram registradas ao término de cada semana e reuniam essencialmente episódios protagonizados pela criança surda no contexto da escola, bem como falas de sua mãe e dos profissionais da escola em referência a ela. 
As observações assumiam natureza participante porque direcionavam as estratégias pedagógicas planejadas pela mediadora pedagógica que contava com o diálogo contínuo de seus professores universitários - o que foi o caso das duas outras autoras deste estudo, para problematização e redirecionamentos a partir do vivenciado.

Para este relato, são trazidas para discussão situações que revelam os obstáculos enfrentados pela família no acompanhamento escolar da criança surda, as dificuldades que a criança surda revelava para sua integração na rotina da turma e da escola, a busca de medidas pelo coletivo da escola para a superação dessas dificuldades e principalmente a forma como a mediadora pedagógica planejava e desenvolvia práticas educativas com a criança surda.

Além disso, nos pautaremos em uma entrevista realizada com a mãe da criança no ano seguinte. Esse relato analisa o cotidiano escolar de uma criança com deficit auditivo, nas suas relações com a família, nas formas como as professoras lidavam com a sua surdez, bem como na mediação da mediadora pedagógica. Considera-se o quanto o deficit sobrepõe o sujeito nas suas relações, impossibilitando que seus pares, principalmente os pais, percebam em seus comportamentos, outros caminhos possíveis para seu desenvolvimento e educação.

\section{LÍNGUA E LINGUAGEM: AS ESCOLHAS DOS PAIS PERANTE O NASCIMENTO DO BEBÊ SURDO}

Inicialmente, baseando-nos em Vygotsky, lembramos que o desenvolvimento do sujeito não deriva apenas do aspecto biológico, mas de tudo o que lhe é proporcionado socialmente. Os sujeitos encontram as ferramentas para seu desenvolvimento nas relações e trocas favorecidas pelo seu entorno, desempenhando a linguagem um papel preponderante. É por meio dela que podemos nos comunicar e nos organizar diante das demandas do meio social, dando nossos primeiros passos nessa direção, ainda enquanto bebês.

A linguagem, segundo Vygotsky (2008), possui duas funções básicas: a de comunicação, para nos relacionarmos uns com os outros, algo que no início da vida é mola propulsora para nosso desenvolvimento e a função de pensamento generalizante, que ordena o real, classifica objetos e situações em categorias e que, ao mesmo tempo, distingue uma coisa da outra. A linguagem exerce, pois, função reguladora do pensamento e, sob essa perspectiva, devemos então, ao estudar a sua construção no indivíduo, voltar nossa atenção para o meio em que ele está inserido, para suas relações interpessoais e para as formas como elas ocorrem. Sua construção se 
dá na dialogicidade do exterior e interior. O homem se relaciona com o mundo, mediado pela linguagem e pela interação (interpretação do outro), afirma Rojo (2010).

Para Pino (2005, p. 156), "a maneira como o cérebro humano vai se configurando, em especial na infância e na adolescência, deve estar diretamente relacionada com as condições concretas que o meio cultural oferece à criança." Assim, é papel do meio cultural a construção da linguagem e da língua, proporcionando a constituição do sujeito. Não somente o sujeito linguístico, mas também, cultural e social considerando sua condição biológica.

Percebe-se, por assim dizer, um vínculo social indesatável entre linguagem e pensamento, vínculo esse a se fortalecer nas instituições sociais, o que no caso de bebês ouvintes tomará corpo nos signos sonoros, prioritariamente.

Vale lembrar também que a personalidade do sujeito não é definida pelas limitações biológicas em si, como é o caso da deficiência auditiva, mas pelas experiências por ele vivenciadas e compartilhadas no ambiente em que está imerso. A criança surda, ao integrar um contexto que viabilize o seu acesso a uma língua que lhe seja suficiente para a construção de sentidos, a significação do mundo, e o estabelecimento das trocas com os diferentes interlocutores, terá seu desenvolvimento semelhante ao de uma criança ouvinte, admitindo-se, para tanto, a possibilidade do uso de línguas diferentes. A fala está ligada à comunicação e não necessariamente ao aparelho fonador; ela pode acontecer em um sistema de signos distintos, como o visual ou o tátil (VYGOTSKY, 2011).

Em se tratando de bebês surdos, principalmente daqueles imersos em lares nos quais a língua materna é oral-auditiva, o que consiste no caso retratado aqui, o questionamento sobre as melhores formas de favorecer o seu desenvolvimento, nesse estreito laço entre linguagem e pensamento, tem sua resposta em um cenário complexo.

Diante do diagnóstico da deficiência auditiva de seus bebês, os pais ouvintes precisam decidir sobre o melhor ambiente linguístico para seus filhos, com predomínio da linguagem oral ou sinalizada. As duas vias irão exigir dos interlocutores dos bebês intensa mobilização, seja na reabilitação oral, seja no aprendizado e uso de uma nova língua: visuoespacial e/ou língua de sinais. Nesse processo de tomada de decisões tão fulcrais, é central que os pais recebam a orientação de uma equipe de profissionais para conhecer e avaliar as consequências possíveis de cada escolha.

As decisões dos pais são difíceis, especialmente porque derivam de um intenso conflito entre abordagens comunicativas, com destaque para o oralismo e o bilinguismo, e porque as 
orientações são ainda médico-tecnicistas, o que inviabiliza as escolhas claramente norteadas pelas necessidades reveladas pelas crianças em seu dia a dia.

De um lado, fundamentando-se no argumento de que a língua partilhada nos espaços sociais como um todo (de modalidade oral-auditiva) pode ser apropriada pelos sujeitos com deficit auditivo, caminha-se rumo à busca de aparatos para o (re)estabelecimento da oralidade, mesmo em condições pouco ou não propícias, como terapias não constantes e trabalho de terapêutico não extensivo a todo entorno da criança. Aqui é muito comum encontrarmos situações em que a fala não faça tanto sentido para a criança com surdez, em vista do acesso parcial aos signos orais-auditivos, insuficientes no processo de significação do que acontece ao seu redor.

Ainda assim, os pais são orientados a matricular seus filhos em escolas comuns, a fim de aumentar o contato com a língua portuguesa, potencializando a fala da criança com deficit auditivo a partir do modelo de seus pares da mesma idade, dos professores e de outros interlocutores com os quais tiver contato.

Tal matrícula na escola comum, uma prerrogativa já apresentada na Constituição Federal de 1988, precisa ser acompanhada de medidas que favoreçam no acesso à escola, a participação, aprendizagem e continuidade nos níveis mais elevados do ensino, sem discriminação e em igualdade de oportunidades educacionais, tendo os alunos suas diferenças respeitadas, consideradas e valorizadas (BRASIL, 2008; 2015). Especificamente, em relação ao aluno surdo, para a garantia desse acesso, a base das iniciativas educacionais é o bilinguismo (BRASIL, 2005), o que não tem se refletido em práticas de escolas comuns.

Do outro lado, e em propostas sustentadas na educação bilíngue, a Libras constitui a primeira língua da criança, referida muitas vezes como sua língua de conforto $^{5}$ e, por isso, precisa ser compartilhada entre os seus interlocutores. A língua portuguesa assume o papel de segunda língua e é apreendida essencialmente na modalidade escrita. Nessa direção, as iniciativas precisam centrar-se na organização de ambientes bilíngues com acesso à língua de sinais nas trocas rotineiras e nos espaços educativos, o que virá a fortalecer os elos entre linguagem e pensamento da criança surda.

O bilinguismo pressupõe, também, a necessidade da descoberta de um mundo visuoespacial e dos vieses das culturas e identidades ${ }^{6}$ que se entrecruzam no compartilhamento das línguas em questão, a Libras e o português, complementa Quadros (2005). Tal abordagem se sustenta na defesa de que os surdos, desde bebês, têm garantido o direito de aprender a Libras e, 
por meio dela, o acesso aos conteúdos curriculares. Para Karnopp e Quadros (2001, p.11), responsabilizar-se pelo

[...] acesso à língua de sinais é garantir a aquisição da linguagem e a aquisição de valores, culturas e padrões sociais que perpassam através do uso da língua. A criança surda precisa ter acesso à LIBRAS e interagir com várias pessoas que usam tal língua para constituir sua linguagem e sua identidade emocional e social.

Quando as crianças surdas chegam à escola, integrando um contexto familiar utente da Libras, elas revelam uma linguagem mais consolidada, o que sabemos não ser o retrato mais comum no Brasil. Nos dias atuais, mesmo as pesquisas apontando o bilinguismo como a perspectiva que melhor corresponde às necessidades dos sujeitos surdos (SKLIAR, 1997; QUADROS, 2005; SILVA; FAVORITO, 2009, LODI; MELO; FERNANDES, 2015; LACERDA; SANTOS; MARTINS, 2016), faz-se recorrente, ainda, a defesa da abordagem oralista, na qual a surdez é vista como um deficit a ser corrigido.

O surdo é visto como um ser anormal, que precisa ter suas funções orais-auditivas restabelecidas. Até hoje, nutre-se a ideia de um sujeito "normal" com um corpo "perfeito" e o desejo de torná-lo mais "aceito" em nossa sociedade (SILVA, 2013). Esse olhar faz com que a pessoa com deficiência auditiva necessite ser vigiada, cuidada e adequada aos padrões sociais, e, nesse sentido, ela deve compreender o mundo sonoro e por essa via se expressar. Contraria-se, no campo da educação, a orientação legal, em que o sujeito surdo, desde a Educação Infantil, deve ter acesso a mediações na Libras, ocupando o idioma português o papel de segunda língua, conforme determina o Decreto n. 5.626 (BRASIL, 2005).

Os pais, preocupados com o bem-estar de seus filhos e seu desenvolvimento social, aderem às iniciativas sustentadas na normalização, sendo-lhes, muitas vezes, negada a possibilidade de compreender as contribuições do acesso à Libras na perspectiva da educação bilíngue, mesmo quando diante de insucessos advindos da reabilitação oral. Nesses casos, consideramos, então, que a aquisição de sua linguagem já foi prejudicada. Defendemos a urgência da organização de tempos, materiais e espaços bilíngues, a iniciar-se desde a matrícula na Educação Infantil.

\section{A HISTÓRIA DE UMA CRIANÇA QUE REPRESENTA MUITAS OUTRAS}

Revista Interinstitucional Artes de Educar. Rio de Janeiro, V. 6, N.2-pág. 578-601 maio-agosto de 2020: "Bebês e crianças: cultura, linguagem e políticas" 
Uma criança nasceu surda e, no decorrer dos seus dois anos de vida, foi diagnosticada clinicamente com surdez profunda em uma orelha e, possivelmente, com autismo. A segunda opção foi descartada, mas a surdez, confirmada. É um menino, o único filho do casal. O pai tem um filho de outra relação, fato relevante, pois pesou na escolha da escola particular. Logo, os pais fizeram a matrícula do filho surdo com base na experiência do irmão ouvinte.

Aos dois anos de idade, ele foi submetido à cirurgia de implante coclear monolateral e era acompanhado por fonoaudióloga e psicóloga. O implante foi realizado na esperança de que a criança viesse a falar com fluência e permanecesse na escola comum, a qual frequentava desde pequeno. Os pais não o reconheciam como surdo, e sim como deficiente que precisava de um tratamento que corrigisse a imperfeição de sua falta de audição, o que gerou a procura pelo implante coclear, decisão muito comum diante do diagnóstico de deficit auditivo, orientados pelos profissionais da medicina e da fonoaudiologia.

Ao ingressar na escola, ainda sem o implante, a surdez não foi revelada à equipe pedagógica. Foi a falta de respostas do pequeno aos estímulos auditivos do ambiente e aos chamados das professoras o que levou as profissionais à suspeita de que havia algo diferente. Somente a partir disso, os pais puderam revelar o diagnóstico de surdez profunda em uma orelha e de uma surdez progressiva na outra, o que, naquele momento, ainda lhe dava algum aproveitamento auditivo para causar dúvidas aos professores. Esse desconhecimento do deficit auditivo levou a escola a matricular duas crianças com deficiência na mesma sala, descumprindo uma regra da instituição de ter somente uma criança, considerada de inclusão, no mesmo grupo.

Após a cirurgia de implante, a criança passou a ser reconhecida na escola como alguém que recentemente estava tendo acesso ao som e, portanto, precisava de um tempo para entenderse nele. O grupo que ela integrava era formado por doze crianças e duas professoras, uma titular e uma auxiliar, que trabalhavam articuladamente conforme a rotina da sala. Visto que as professoras da sala não estavam conseguindo lidar com as peculiaridades apresentadas pela criança, uma das profissionais da escola, que estava no final de contrato, foi convidada a ocupar a vaga de acompanhante terapêutica - AT, denominação dada pela escola para o papel de mediadora pedagógica, como passaremos a chamá-la, com a anuência dos pais, ficando os encargos financeiros da contratação sob a responsabilidade deles.

É preciso aqui ponderar o risco que há na prática de contratação de agentes de apoio em unidades escolares das redes pública e privada em detrimento da organização do Atendimento Educacional Especializado (AEE), estando tais agentes em processo de formação em cursos de licenciaturas. Documentos legais como a Política Nacional de Educação Especial na Perspectiva 
da Educação Inclusiva (BRASIL, 2008), o Decreto de Lei no 7.611, que dispõe sobre a Educação Especial e o atendimento educacional especializado (BRASIL, 2011) e, mais recentemente, a Lei n. 13.146, que institui a Lei Brasileira de Inclusão da Pessoa com Deficiência (BRASIL, 2015) estabelecem importantes orientações para o profissional que atuará no AEE, exercendo um trabalho articulado aos professores das salas comuns com o intuito de se assegurar o acesso a uma educação efetiva aos alunos com deficiência.

O risco na contratação dos agentes de apoio ou comumente estagiários se faz eminente nas escolas quando a atuação de tais profissionais não é acompanhada por profissionais de AEE, o que é caso da escola deste relato, e/ou quando exercem um trabalho substitutivo ao ensino comum. A Política Nacional de Educação Especial estabelece que os serviços de apoio são complementares ou suplementares ao ensino regular e exercidos por profissionais especializados (BRASIL, 2008). Os licenciandos no exercício da mediação pedagógica precisam receber a supervisão professores que atuam em classe comum e no AEE, sendo este último inexistente na escola-campo aqui tratada. Na figura da mediadora pedagógica, a criança surda deposita suas melhores chances de ser descoberta como sinalizante, conforme revela o vivido por ela no cotidiano da escola.

$\mathrm{Na}$ ausência de uma linearidade de ações que estabelecessem continuidade entre abordagens estabelecidas com a criança deficit auditivo, as pessoas reconheciam o menino como alguém que estava conhecendo um novo mundo, o dos sons, e que ainda estava atribuindo sentido a ele. Desta forma, a perspectiva de outra língua não foi considerada. Por parte da mãe, havia o conhecimento da existência de outras possibilidades de educação para o filho, no entanto, uma escola bilíngue para surdos, ou a aquisição da língua de sinais, não foi considerada pela fonoaudióloga que a acompanhava e orientava os pais, acreditando que o uso de alguns sinais ou gestos como apoio seria suficiente para o aprendizado da língua oral, o objetivo de todos naquele momento.

Neste sentido, uma fala da mãe pode ser destacada, na qual fica explícito que, ao referirse ao desenvolvimento da fala do filho, buscava-se não somente estabelecer uma forma de comunicação, mas o trânsito dos pais no seu grupo social de origem. A ausência da fala da criança excluía a mãe do grupo de mães da sala de seu filho: "sinto que os pais das outras crianças me olham diferente por causa da condição de meu filho".

Para além dessa fala, ficava explicitada a exclusão de todo o grupo familiar. Assim, se o grupo familiar estava excluído, o ninho do bilinguismo, assim nomeado por Kyle (1997), estava vazio, conforme constatado por Campos (2017) no qual os pais não dominam a língua de sinais 
e, desta forma, não possibilitam que as crianças tenham o contato com a língua no núcleo familiar. Sobressaem-se contextos em que a língua de sinais é desconsiderada.

A fala é considerada a língua legítima, e a abordagem oralista dá aos pais exatamente aquilo que buscam: fala. Vale ressaltar ainda o peso que tem a fonoaudiologia para os pais logo após a descoberta da surdez. A fonoaudiologia ocupa um papel de saber, um saber científico que determina o que deve ou não ser feito para cada criança (SANTANA, 2007, p.121).

Entre os familiares, alimentava-se a expectativa de que a criança com deficit auditivo aprenderia a falar como os pares ouvintes. "Meu filho precisa falar logo, olha lá as outras crianças conversando, e ele não pode fazer o mesmo" (sic mãe). Na mesma proporção em que os pais se distanciavam da Libras, a criança continuava insistindo no uso do canal que lhe era pleno: a visão. Nesta perspectiva, o papel do educador, aqui representado por uma mediadora pedagógica, torna-se determinante para o desenvolvimento da língua e do discurso da criança.

As atividades realizadas em língua oral eram respondidas pelo pequeno com choros, gritos e fugas. Assim, nas rodas de conversa, momento em que todos da sala eram convidados a contar sobre seu fim de semana, ou quando eram orientados sobre a rotina do dia, ele tinha que ficar sentado prestando atenção a um estímulo que não acessava.

A rotina era informada na língua oral, e a criança buscava, à sua maneira, ocupar seu espaço discursivo. Ela corria pela sala, jogava-se no chão, tirava os sapatos, os aparelhos, e assim confirmava sua busca por interlocução, até então solitária. Um discurso já era corrente na escola em todos os turnos, sendo disseminado por falas como: "Nossa! Tem um aluno no período da tarde que é muito difícil de se trabalhar"; "Acho que além de ser surdo, tem algum outro problema"; "As professoras dele estão de parabéns, porque aguentar o trabalho que ele dá não é fácil"(sic profissionais da escola).

Estando representado como deficiente, acionar uma mediadora pedagógica se tornou imperativo, ainda que fosse ocupada por uma pessoa em formação inicial.

\subsection{NA MEDIADORA PEDAGÓGICA, UMA INTERLOCUÇÃO POSSÍVEL}

A ideia de contratar uma mediadora pedagógica, e denominada pela escola como acompanhante terapêutica, veio intimamente ligada ao deficit auditivo. Assim, era a expectativa que seu fazer, apesar de ocupar o espaço escolar, fosse orientado pela terapeuta do caso e, nesse 
contexto, a língua de sinais se faria presente por sinais isolados, conforme orientação da fonoaudióloga.

Objetivado pelas professoras e orientado pela fonoaudióloga, esse tipo de apoio nos faz lembrar de um período histórico em que as práticas educativas com crianças pequenas do jardimde-infância, atual Educação Infantil, eram intensamente marcadas pelo cuidado, distando-se do educar. Nessa direção, a natureza do apoio, que se delinearia na atuação da mediadora pedagógica, revelava um risco exponencial: da organização de uma rotina para a criança surda toda centrada em uma visão clínico-patológica; e, como se em um retrocesso até mesmo dos avanços alcançados no campo da educação da criança pequena, ela deixaria de ser compreendida como ator social, segundo seus interesses, suas curiosidades e sua multiplicidade de expressões.

Apesar da inexperiência da funcionária, o cargo de acompanhante terapêutica foi ocupado por uma estudante do curso de pedagogia, que possuía um conhecimento básico da Libras. Essa seria a primeira experiência da profissional no papel em questão. Ao conhecer a criança, a estudante se viu na obrigação de procurar informações teóricas sobre alunos surdos com implante coclear e opções de trabalho com os mesmos, e a revisitar suas vivências de formação com foco na Educação Infantil.

Nessa busca teórica, a mediadora pedagógica deparou-se com as pesquisas sobre educação bilíngue para surdos e com a Libras. Tal conhecimento, ainda que inicial, estimulou um olhar mais sensível para as necessidades da criança naquele momento, o que foi determinante para a ressignificação de todos os cenários de interlocução nos quais a criança circulava. As iniciativas da mediadora pedagógica começaram a se distanciar da visão clínico-patológica, que derivaram de uma observação atenta à criança, com a intenção de considerá-la em sua diversidade de manifestações, bem como da escuta e do diálogo com a fonoaudióloga, os profissionais da escola e os pais.

A mediadora pedagógica, em sua atuação, tendo um olhar específico para a acessibilidade da criança surda, buscava meios para, a partir dos objetivos das propostas pedagógicas da instituição, organizar recursos e estratégias que mais a aproximassem das vivências promovidas no contexto da turma, que considerassem as suas diferentes linguagens nas trocas cotidianas e que partissem de uma construção coletiva de seus interlocutores, conforme estabelecem as Diretrizes Curriculares Nacionais para a Educação Infantil (BRASIL, 2009).

A licencianda, atuando como mediadora pedagógica, enquanto estabelecia pequenas mudanças na rotina da criança, com o objetivo de atender às necessidades reveladas por ela, 


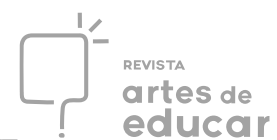

reconhecia, ao mesmo tempo, seus limites no conhecimento da Libras e promovia relevantes alterações, não somente no dia a dia da criança, mas nos olhares que lhe eram direcionados.

A mediadora pedagógica passou a organizar práticas que destacavam os estímulos visuais em importantes momentos da rotina. Nas rodas de conversa, por exemplo, onde até então era usada somente a fala, passaram-se a utilizar gestos negociados entre a agente de apoio e a criança, mesclados a alguns sinais da Libras. As figuras que ilustravam as rodas de conversa tomaram papel central nos momentos de interação.

No início da sua atuação, levar a criança a compreender sua rotina foi a tarefa em que a mediadora pedagógica encontrou maior dificuldade, pois ela recusava-se a permanecer sentada na roda e não havia uma forma de comunicação que mediasse a interação. Algumas estratégias foram encontradas e acordadas com a família, os profissionais da escola e as terapeutas.

A criança passou a ocupar um lugar mais próximo das professoras, e as ilustrações, já utilizadas nas atividades, serviram de apoio para ela. Ao colocá-la ao lado das docentes, fica explicitado que o desenvolvimento da língua oral ainda era o objetivo principal do trabalho desenvolvido, pois todos os profissionais acreditavam que a distância do interlocutor dificultava a compreensão da fala e, uma vez mais, a visualidade era tomada como apoio, como nos momentos quando a turma era convidada a comentar sobre o fim de semana, conforme registrado no diário de campo da mediadora:

Passamos a explorar o fim de semana dele por meio de imagens. Toda segundafeira, ele traria um caderno com imagens que lembrassem seu fim de semana. Quando chegava a sua vez de contar sobre sua experiência, ele levantava, expressava felicidade e mostrava para cada colega as imagens.

Embora o uso do caderno fosse uma importante estratégia que aproximava os colegas da turma dos acontecimentos do fim de semana da criança surda, a sua participação continuava sendo parcial. A falta de uma língua barrava a sua interação efetiva com as demais crianças por mais que essas se mostrassem curiosas por conhecerem mais sobre as imagens contidas no caderno, barreira essa também presente nos momentos de parque. De uma rotina de isolamento no parque, a mediadora pedagógica, por meio da organização de brincadeiras com a criança, passa a observar a presença de colegas da turma ao seu redor, possibilitando alguma interação. Ainda assim, impunham-se os limites da privação do acesso a uma língua que viabilizasse o prosseguimento das trocas com os adultos e seus pares coetâneos.

De modo semelhante, nas atividades envolvendo o inglês, um dos poucos momentos em que a criança se sentia integrada, sem se dispersar, havia o uso contínuo de músicas, sempre 
acompanhadas da gestualidade e de imagens como apoio. Em cada ação realizada pelo menino, ele sempre recorria ao meio visual e, por isso, eram tão atrativas as propostas em inglês. A professora intensificava suas expressões faciais e corporais, o que contribuía para que ele se identificasse e buscasse compreensão de parte do que ela dizia.

Nesses cenários, a fala é o que se destaca, predomina. Toma-se aqui, como referência, as contribuições de Silva (2013, p. 43):

Consideramos que o processo educacional do surdo implantado deve ser embasado por políticas que se fundamentem no respeito à diferença, construindo um ensino que desenvolva sua língua, sua identidade, dentro outros aspectos. Uma política que proporcione a esses sujeitos uma vida escolar mais significativa e contextualizada, desvinculada da visão clínica, que pode ocasionar prejuízos à aprendizagem.

Na perspectiva da autora, a diferença do aluno deve ser respeitada na sua integralidade, no entanto, a representação de ouvinte, que é carregada pelo sujeito deficiente auditivo, dificulta a percepção de que o estímulo auditivo não supre suas necessidades linguísticas, cognitivas, entre outras. Nos ambientes que circundam a criança, nega-se a possibilidade de compreendê-la como um ser surdo ${ }^{7}$, um sujeito cultural que encontra, na Libras, uma forma de comunicar-se e constituir-se no mundo.

A criança surda e implantada insistia. Ela procurava, frequentemente, referenciais visuais que pudessem guiar sua rotina; fotos, cores fortes, desenhos e gestos eram signos que ajudavam a criança a acompanhar o grupo. Assim, a mediadora pedagógica foi autorizada a usar alguns sinais da Libras nas atividades da rotina escolar, e a criança passou a incorporar os sinais, procurando uma produção mais próxima possível do seu interlocutor, mais uma demonstração do quanto a língua visual atendia às suas necessidades.

Podemos, então, recorrer à Vygotsky (2007), quando ressalta a importância do interlocutor mais experiente. O papel da mediadora pedagógica mostrou-se fundamental, não somente para a criança, mas para todos com os quais ela se relacionava. Deste modo, o futuro da criança começou a ser repensado, pelos pais e pela escola.

Ao final de um semestre, a estudante de pedagogia se despediu da função, e a escola não encontrou outra profissional com suas características. Para a mãe, seu filho foi abandonado e regrediu, conforme relata na entrevista realizada pela mediadora:

[...] os dias foram se passando e comecei a ver meu filho novamente como antes. Não participava da roda, não brincava com seus novos amigos. Então, tivemos uma conversa e você me disse que tinha certeza que meu filho iria dar 
um salto em seu desenvolvimento quando tivesse acesso à Libras; essa fala ficou em minha mente durante muito tempo. Então, resolvi perguntar para as fonoaudiólogas se elas conheciam uma escola que pudesse ajudar meu filho; já não sabia mais o que fazer.

Nesse contexto, a educação bilíngue para surdos foi considerada no percurso escolar da criança. A fonoaudióloga avaliou que os avanços esperados no desenvolvimento da oralidade não foram alcançados. Mesmo com o implante coclear em uso, com os estímulos solicitados e com as terapias frequentadas, a profissional teve a percepção de que o paciente oferecia melhores resultados na presença de estímulos visuais e, principalmente, da língua de sinais, fazendo, assim, com que a uma escola bilíngue para surdos fosse uma possibilidade.

Vemos nesse caso semelhança com os dados encontrados em Valadão et al (2012). Os autores apresentam o estudo de caso de uma criança implantada na mesma faixa etária do participante deste estudo e que precisou passar por dois anos de espera após o implante até que a Libras fosse inserida em sua rotina; primeiro, era preciso aguardar a comprovação do insuficiente desenvolvimento de habilidades auditivas e de língua oral.

Situações como essas nos levam a dimensionar o impacto da busca pela normalização da criança. Diante do cenário de acesso tardio a Libras tão comum, um questionamento ecoa: qual é o custo da imersão tardia em ambientes em que Libras seja a língua de interlocução no desenvolvimento dos sujeitos? Linguagem e pensamento já terão sido prejudicados. Se o acesso a uma língua é o que se deixa para depois, nega-se à criança o acesso a tudo o que a linguagem representa na vida humana: a invenção, a criatividade, a narração, a ficção, a vida em comunidade, a exposição ao mundo, a escrita, a leitura, enfim, a tudo o que torna o homem um ser humano, assevera Skliar (2017).

$\mathrm{Na}$ contramão da justificativa pujante de que tal inserção viria a prejudicar o desenvolvimento da oralidade, Kelman (2010) revela as contribuições de práticas fundamentadas no bilinguismo também para crianças implantadas. Para a autora, o implante torna-se mais uma opção para que o sujeito seja bilíngue, utilizando cada língua a depender do cenário de interlocução.

O bilinguismo em crianças com implante coclear deve ser estimulado, pois a pessoa que sabe mais de uma língua está melhor preparada para a vida. Um surdo que fale e sinalize pode transitar em mais espaços e contextos socioculturais do que aquele que é usuário exclusivo de língua de sinais (KELMAN, 2010, p. 37). 
Chamamos atenção para a necessidade de que as medidas a serem tomadas junto ao cotidiano da criança surda implantada sejam aquelas que forneçam as bases para a socioconstrução da linguagem e, desse modo, sejam suficientes para a significação dos saberes escolares, rompendo com um cenário que enfatize um ou outro código linguístico. Os terapeutas, professores e gestores envolvidos nesse processo precisam assumir a posição de mediadores, profissionais aptos a reconhecerem e avaliarem as habilidades e dificuldades dos alunos para, então, redirecionarem continuamente suas ações e num suporte também contínuo aos familiares. Em vez disso, na escola da criança participante deste estudo, a saída da mediadora pedagógica leva a mãe perceber que o filho não demonstra a mesma motivação pela escola, não participa como antes das atividades da rotina, chegando a parecer regredir em seu desenvolvimento.

Apesar de ter finalizado o acompanhamento à criança como profissional, a antiga mediadora pedagógica da escola tornou-se uma referência para a escolha da nova escola. Ela conseguiu ressaltar para a mãe os pontos de mais atenção do filho e, nesses momentos, a língua de sinais marcou sua presença, o que fez com que a mãe aceitasse visitar uma escola para surdos com abordagem educacional bilíngue, língua de sinais e língua portuguesa.

Para Pino (2005, p. 38),

[...] parece perfeitamente razoável pensar que se a fala é a mais proeminente das formas de comunicação humana, ela não é a única daquelas que constituem o universo semiótico em que todas as coisas adquirem significação, constitutivo essencial de qualquer forma de comunicação humana.

Ainda que por caminhos pouco tranquilos, a criança em questão encontrou uma interlocutora que reconheceu suas possibilidades para além da fala, desvendando sua marca de humanidade nos seus indícios, até então, não verbais. Para o autor, a inserção do bebê humano no estranho mundo da cultura passa, necessariamente, por uma dupla mediação: a dos signos e a do Outro, detentor da significação. No processo aqui analisado, a mediação do outro apresentouse turvada pela representação negativa do deficit auditivo. Foi neste complexo contexto que surgiu a disponibilidade de conhecer um novo caminho.

\subsection{CONHECENDO A ESCOLA, RECONHECENDO O FILHO}

Algum tempo depois de ter matriculado o filho na escola para surdos, o discurso da mãe se modificou. O filho deficiente foi, paulatinamente, transformando-se em surdo. O discurso da 
exclusão foi reconsiderado pelos novos encontros. Ao visitar a escola, a mãe reconheceu que seu filho não era o único surdo e, assim sendo, ela também não estava sozinha. Embora estivesse frente à outra exclusão, os pais surdos de crianças surdas agora ocupavam o lugar dos que estranhavam, seu filho implantado estava em uma escola onde as pessoas sinalizavam.

Com a mudança, a culpa de não ter oferecido o que o filho necessitava emergiu na fala mãe:

[...] percebo que eu não dei o que ele tanto me pedia indiretamente que era ser compreendido, sabe..., foi com a ajuda de pessoas como você que tinha um olhar sensível para ele, que percebi que eu tinha de ajudá-lo. Acho que foi errando que eu aprendi e entendi que meu filho é surdo e que ele precisa de pessoas como ele ao seu redor, para saber que ele não é o único surdo [...]

De uma posição de distanciamento da criança, a mãe identificou um papel ativo a ser exercido por ela na promoção do bem-estar do filho surdo. Assim como as mães investigadas em Kelman et al. (2011) e Valadão et al (2012), aqui foi requerido certo tempo e orientação profissional até o reconhecimento da importância da Libras no cotidiano da criança. Articuladamente a essa compreensão, abriu-se espaço para a observação, segundo as possibilidades de desenvolvimento reais e potenciais do filho, mesmo ele tendo dado continuidade ao acompanhamento fonoaudiológico, rompendo com a prioridade que assumia o ciclo de objetivação da fala oral instaurado desde o diagnóstico da surdez.

[...] você não imagina a alegria dele, quando percebeu que estava rodeado de crianças como ele; elas falavam com o olhar, com o corpo e muitos já sabiam alguns sinais. Ele ficou tão feliz, que foi difícil levá-lo para casa... Quase toda semana, ele traz um amigo até em casa ou vai até a casa deles para brincar (a mãe se emociona).

A Libras passou a ser compreendida como uma língua que qualifica as trocas da criança surda em seu meio social e a construção de vínculos com seus pares coetâneos, ao que a mãe complementa:

Sinto que meu filho hoje é feliz, ele entende que pode ser compreendido e encontrou crianças iguais a ele. Não precisa mais ser comparado a outras crianças, e eu finalmente vou conseguir conversar com meu filho, através da Libras. Se eu pudesse ter vencido a barreira do preconceito com meu próprio filho antes, talvez não tivesse passado por momentos de agonia e insegurança. Hoje, meu filho é feliz, e eu ainda mais.

Para além da escolha de uma escola, uma criança foi desvendada por detrás da deficiência, e foi uma mediadora, sensibilizada pela formação e informação, que orientou e 
acompanhou o delicado processo que aqui brevemente relatamos. A mãe que, depois de um duradouro e intenso percurso, reconheceu seu filho como surdo e terá que dar continuidade ao longo trajeto que tem a percorrer. Na perspectiva de Pino (2005, p. 53),

[...] a humanização da espécie é uma 'tarefa coletiva', enquanto a humanização de cada indivíduo é 'tarefa do coletivo'; e, de outro lado, que humanização da espécie confunde-se com o processo de produção da cultura, enquanto que humanização do indivíduo confunde-se com o processo de apropriação da cultura.

No caminho de cada um tomar seu papel na tarefa que a história nos impõe, de introduzir cada indivíduo na cultura, a figura da criança precisará, ainda, ser descortinada por parte de outros familiares, como o pai que restringiu o contato com o filho, após seu ingresso na escola para surdos, de profissionais que venham a atuar com ela e de outros interlocutores. A descoberta da centralidade da língua de sinais no desenvolvimento do filho passa a requerer da mãe que reserve parte de sua energia no aprendizado de uma língua que lhe é nova e em outros aprendizados que decorrerão do porvir.

\section{CONSIDERAÇÕES FINAIS}

Escola, família e clínica fonoaudiológica, estamos falando de uma complexa teia a se compor frente a importantes decisões relacionadas à vida de bebês surdos.

Assim como aconteceu durante séculos, mesmo depois do reconhecimento da Libras, os papéis da escola e da clínica fonoaudiológica se amalgamam, determinando os caminhos a serem seguidos pelos pais. Mesmo descontentes, por vezes angustiados, eles não se consideram capacitados para tomar decisões a respeito do filho e, ainda que não intencionalmente, a atuação dos profissionais distancia os pais de suas percepções mais sensíveis. Os protocolos profissionais turvam o olhar para a criança.

A escola e a clínica deste relato carecem de uma atuação articulada no apoio à criança e família. De um lado, a escola esperava na figura da atuação exclusiva de uma mediadora pedagógica que a criança fosse integrada na turma de Educação Infantil, ainda que não fosse percebido qualquer outro movimento da instituição no sentido de que a criança pertencesse àquele espaço. Do outro lado, da clínica fonoaudiológica, a reabilitação oral e auditiva é o alvo colocado acima de outras necessidades no desenvolvimento da criança. 
Em meio a esse cenário, há uma família buscando ser orientada e ao mesmo tempo suprir seu próprio desejo, buscando atender a um, escola, e a outro, terapeuta; e uma criança torna-se invisível até que seja descoberta como sinalizante na atuação da mediadora pedagógica, principal elo para que alguma articulação com o trabalho das professoras da sala fosse tecida, e as exigências terapêuticas atendidas.

Mas, o elo não sendo um objetivo institucional perde-se com o término de contrato da profissional em formação no curso de Pedagogia, mostrou-se frágil naquele contexto e forte na sua subjetividade. Assim, ainda que o trabalho institucional fosse finalizado, a ação da agente pedagógica reverbera na mãe que retoma as decisões sobre sua criança e age no sentido do que entende ser o melhor para ela.

Neste relato, nota-se que tempo e experiências, de maneira fragmentada, foram viabilizados no percurso dos pais para o reconhecimento do filho como surdo, por pelo menos um deles. A inexistência da atuação de uma equipe multidisciplinar dificultou a compreensão da criança em suas singularidades, que vai além do deficit auditivo. A ausência de um ambiente linguístico, que proporcionasse experiências com a Libras na escola, foi outro importante obstáculo para a família e, principalmente, para a criança que, mesmo tendo muito a dizer em sua infância, pôde compartilhar apenas sentidos parciais pela via dos estímulos que lhes eram acessíveis.

O posicionamento da escola em relação ao apoio à criança foi visto como o suficiente para a organização de seu trabalho. As orientações da mediadora pedagógica, mesmo estando em formação inicial, foram consideradas como suficientes para estabelecer as diretrizes do desenvolvimento da criança; o atendimento educacional especializado não foi considerado como necessário.

Escola e clínica pareciam não identificar o emaranhado de fios que compunha a teia e, se caso o tivessem identificado, permaneceram nos caminhos próprios de seu domínio. Foi neste cenário que o papel da mediadora pedagógica se tornou determinante como aquela que apresentou a língua de sinais, não somente para a criança, mas para a escola e para a família, de forma contundente, pois demonstrou, nas suas vivências, a criança como sujeito de interação; foi a profissional que exerceu a escuta atenta à criança, percebendo nela os benefícios de uma interlocução na Libras e na apreensão e relacionamento com o mundo por formas visuais prioritariamente, como no planejamento de recursos e estratégias que garantissem alguma participação sua na rotina da turma. 
Este artigo, debruçando-se no conhecimento do percurso de uma criança surda recémimplantada matriculada na Educação Infantil - modalidade essa que requer a intensificação de investigações que contemplem especificidades da criança surda pequena, revela a necessidade de se realizar um trabalho integrado nas áreas da saúde e da educação nos primeiros anos de desenvolvimento da criança em uma escuta atenta as suas habilidades e dificuldades, o que deverá direcionar os rumos da organização de projetos educativos inclusivos e, por decorrência, bilíngues - unimodal ou bimodal.

Ao perder-se a relação entre todos os interlocutores, com os quais a criança interage, perde-se também a infância, pois esta fica subjugada aos cuidados terapêuticos. Assim, é fundamental que o a criança seja assistida como criança, seja em que espaço ocupe, e que os profissionais não se esqueçam do espaço tempo ocupado por esse sujeito.

\section{REFERÊNCIAS}

ANDREIS-WITKOSKI, S.; FILIETAZ, M. R. P. (Org.). Educação de surdos em debate. Curitiba: Ed. UTFPR, 2014, p. 41-50.

BRASIL. Lei $\mathbf{n}^{\mathbf{0}}$ 10. 436, de 24 de abril de 2002, que dispõe sobre a Língua Brasileira de Sinais - Libras. Brasília: Presidência da República, 2002.

Decreto n. 5.626, de 23 de dezembro de 2005. Regulamenta Lei ${ }^{\circ} 10$. 436, de 24 de abril de 2002, que dispõe sobre a Língua Brasileira de Sinais - Libras, e o art. 18 da Lei $\mathrm{n}^{\circ} 10.098$, de 19 de dezembro de 2000. Disponível em: http://www.planalto.gov.br/ccivil_03/_ato20042006/2005/decreto/d5626.html. Acesso em: 29 abr. 2019.

Política Nacional da Educação Especial na Perspectiva Inclusiva. Documento elaborado pelo Grupo de Trabalho nomeado pela Portaria Ministerial $\mathrm{n}^{\circ} 555$, de 5 de junho de 2007, prorrogada pela Portaria $n^{\circ} 948$, de 09 de outubro de 2007, entregue ao Ministro da Educação em 07 de janeiro de 2008. Brasília: Presidência da República, 2008.

Decreto n. 6.949, de 25 de Agosto de 2009. Promulga a Convenção Internacional sobre os Direitos das Pessoas com Deficiência e seu Protocolo Facultativo, assinados em Nova York, em 30 de março de 2007. Disponível em: http://www.planalto.gov.br/ccivil_03/_ato20072010/2009/decreto/d6949.htm. Acesso em: 29 fev. 2020.

Resolução n. 5, de 17 de Dezembro de 2009. Fixa as Diretrizes Curriculares Nacionais para a Educação Infantil, Brasília: MEC, SEB, 2009. Disponível em: http://www.seduc.ro.gov.br/portal/legislacao/RESCNE005_2009.pdf. Acesso em 14 out. 2019.

Decreto n. 7.611, de 17 de Novembro de 2011. Dispõe sobre a educação especial, o atendimento educacional especializado e dá outras providências. Brasília: Presidência da República, 2011.

Revista Interinstitucional Artes de Educar. Rio de Janeiro, V. 6, N.2-pág. 578-601 maio-agosto de 2020: "Bebês e crianças: cultura, linguagem e políticas" 


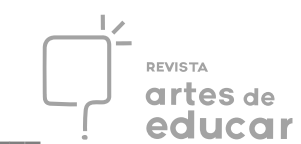

Lei n. 13.146, de 6 de julho de 2015. Institui a Lei Brasileira de Inclusão da Pessoa com Deficiência (Estatuto da Pessoa com Deficiência). Brasília: Presidência da República, 2015.

CAMPOS, S. R. L. de. A representação social dos professores de surdos sobre o ensino de Libras e Língua Portuguesa no Ensino Fundamental I. Tese de Doutorado. Universidade de São Paulo, São Paulo, 2017.

GURGEL, T. M. A.; TURETTA, B. A. R.; ROSA, L. A.; SILVA, R. R. da. "Aquisição de LIBRAS na Educação Infantil um trabalho a partir de narrativas". In LACERDA, C. B. F.; SANTOS, L. F. dos; MARTINS, V. R. O. (Orgs), Escola e Diferença: caminhos para educação bilíngue de surdos. São Carlos: EdUFSCar, 2016, p. 65-78.

HIGGINS, P.C.; "Outsiders in a hearing world? a sociology of deafness", Sage Publications, Inc, London 1980.

KARNOPP, L.; QUADROS. R. M. de. "Educação Infantil para surdos”. In: ROMAN, E. D.; STEYER, V. E. (Org.). A criança de 0 a 6 anos e a educação infantil: um retrato multifacetado. Canoas, 2001. p. 214-230.

KELMAN, C. A. Dilemas sobre o implante coclear: implicações linguísticas e pedagógicas. Revista Espaço: Informativo técnico-científico do INES, n. 33, jan./jun. 2010, p. 33-41.

KELMAN, C. A.; et al. Surdez e família: facetas das relações parentais no cotidiano comunicativo bilíngue. Linhas Críticas, v. 17, n.33, p. 349-366, 2011.

KRAEMER, G. M. Identidade e cultura surda. In: LOPES, M. C. (org). Cultura surda e Libras, Unisinos. 2012. p. 138-153. Disponível em: http://projetoredes.org/wp/wpcontent/uploads/Cultura-Surda-e-Libras.pdf. Acesso em: 29 de abr. 2019.

KYLE, J. O. "O ambiente linguístico: alguns comentários sobre o desenvolvimento do bilinguismo". In: SKLIAR, C. (Org.) Atualidade da educação bilíngue para surdos. Porto Alegre: Mediação, 1997, p. 106-117..

LACERDA, C. B. F. de; SANTOS, L. F. dos; MARTINS, V. R. de O. (orgs). Escola e diferença: caminhos para a educação bilíngue de surdos. São Carlos: Edufscar, 2016.

LODI, A. C. B.; MELO, A. D. de; FERNANDES, E. 2. Letramento, bilinguismo e educação de surdos. São Paulo: Mediação, 2015.

LOPES, M. C.; VEIGA-NETO, A. "Marcadores culturais surdos". In: VEIGA-MACHADO, L. Matos da Costa; LOPES, M. C. Educação de surdos: políticas, línguas de sinais, comunidade e cultura surda. Santa Cruz do Sul: Edunisc, 2010. p. 116-137.

PINO, A. As Marcas do Humano: às origens da constituição cultural da criança na perspectiva de Lev S. Vigotski. São Paulo: Cortez Editora, 2005.

QUADROS, R. M. de "O bi do bilinguismo na educação de surdos". In: Surdez e bilinguismo. Porto Alegre: Mediação, 2005, p. 26-36. 
. "O "bi" em bilinguismo na educação de surdos". In: LODI, A. C. B.; MELO, A. D. B.; FERNANDES, E. Letramento, bilinguismo e educação de surdos. Porto Alegre: Mediação, 2015. p. 187-200.

ROJO, R. H. R. Falando ao Pé da Letra: a construção da narrativa e do letramento. 1. ed. São Paulo: Parábola, 2010.

SANTANA, A. P. Surdez e linguagem: aspectos e implicações neurolinguísticas. 5. ed. São Paulo: Plexus, 2007.

SILVA, I. R.; FAVORITO, W. Surdos na escola: letramento e bilinguismo. Brasília: MEC/SEESP, 2009.

SILVA, J. A. S. A educação da Criança surda com implante coclear: reflexões sobre a família, a clínica e a escola. Dissertação de Mestrado. Universidade Federal do Espirito Santo, Vitória, 2013.

SILVA, I. R. Educação bilíngue para surdos e valorização de línguas minoritárias. Estudos linguísticos, São Paulo, v. 44, n. 2, p. 574-583, maio/agosto 2015. Disponível em: <https://revistas.gel.org.br/estudos-linguisticos/article/view/995> Acesso em: 23 jan. 2020.

SKLIAR, C. (org.). Educação e exclusão: abordagens sócio-antropológicas em educação especial. Porto Alegre: Mediação, 1997.

SKLIAR, C. .(org). “Apresentação: a localização política da educação bilíngue para surdos”. In: SKLIAR, C. Atualidade da educação bilíngue para surdos: interfaces entre pedagogia e linguística. 6. ed. Porto Alegre: Mediação, 2016. p. 7-14.

SKLIAR, C. As diferenças e as pessoas surdas. Fórum, Rio de Janeiro, n. 36, p. 15-22, jul./dez. 2017.

VALADÃO, M. N. et al. Língua Brasileira de Sinais e implante coclear: relato de um caso. Revista Educação Especial, Santa Maria. v. 25, n. 42, p. 89-100, jan./abr. 2012.

VIGOSTSKI, L. S. A formação social da mente. São Paulo: Martins Fontes, 2007.

VYGOTSKY, L. S. A defectologia e o estudo do desenvolvimento e da educação da criança anormal. Educação e Pesquisa, v. 37, n.4, p. 861-870, 2011.

VYGOTKSY, L.S.. Pensamento e linguagem. 4. ed. São Paulo: Martins Fontes, 2008.

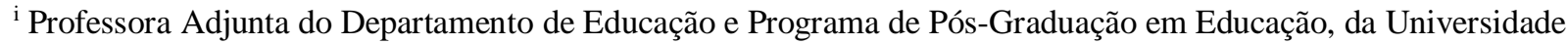
Federal de São Paulo (Unifesp), campus Guarulhos, São Paulo, Brasil. E-mail: egarrutti@ yahoo.com.br. ORCID: https://orcid.org/0000-0001-7566-6569

ii Professora Adjunta do Departamento de Letras e Coordenadora da Coordenadoria Apoio Pedagógico e Atividades Complementares (CAPAC) e Coordenadoria Técnica de Acessibilidade e Inclusão (CTAI) da Pró Reitoria de Assuntos Estudantis (PRAE), Universidade Federal de São Paulo (Unifesp), Campus Guarulhos, São Paulo, Brasil. E-mail: srlcampos@yahoo.com.br. ORCID: https://orcid.org/0000-0003-3437-605X
} 
iii Licenciada no curso de Pedagogia, Universidade Federal de São Paulo (Unifesp), Campus Guarulhos, São Paulo, Brasil. E-mail: jessicaoliveiraholanda@gmail.com. ORCID: https://orcid.org/0000-0001-6479-5787

${ }^{4}$ Neste estudo, escolhemos utilizar a expressão "mediadora pedagógica" ao invés de "acompanhante terapêutica" uma vez que, embora a escola revele uma abordagem clínico-terapêutica na terminologia adotada, o papel exercido pela estudante do curso de Pedagogia é de alguém que significa o vivido a partir da perspectiva da educação.

5 No conceito desenvolvido por Higgins (1980), o surdo encontra conforto e confiança ao usar a língua de sinais, pois, dentro de sua comunidade, a comunicação é garantida, e nela ele encontra, ainda que não completamente, respostas para as insuficiências na interação com o ouvinte.

6 Pressupõe-se a importância do contato do aluno surdo com outros surdos para a construção de uma identidade surda. A cultura e a identidade surda são retratadas como sendo um campo em que são produzidos diferentes sujeitos e identidades. Segundo Kraemer (2012, p. 141-142), "as identidades dos sujeitos são múltiplas, e em função das variadas posições assumidas por cada um se elabora um processo de identificação próprio a cada sujeito".

${ }^{7}$ Lopes e Veiga-Neto (2010, p. 116), com o objetivo de mostrar que a expressão ser surdo abrange uma experiência de ser, de estar no mundo, que é vivida no coletivo e sentida de maneiras particulares, pontuam "além da língua de sinais, da arte, do teatro e da poesia surda, a noção de luta, a necessidade de viver em grupo e a experiência do olhar são marcadores que nos permitem falar de identidades surdas fundadas em uma alteridade e uma forma de ser surdo". 